\title{
Childhood adversity and women's cardiometabolic health in adulthood: associations with health behaviors, psychological distress, mood symptoms, and personality
}

\author{
Lotte van Dammen ${ }^{1,2,3^{*}}$ (D), Nicole R. Bush ${ }^{4,5}$, Susanne R. de Rooij ${ }^{6}$, Ben Willem J. Mol ${ }^{8}$, Henk Groen ${ }^{3}$,
} Annemieke Hoek ${ }^{2}$ and Tessa J. Roseboom ${ }^{6,7}$

\begin{abstract}
Background: We tested whether childhood adversity is associated with poor cardiometabolic health in adulthood among a sample of overweight or obese Dutch women of reproductive age. Health behaviors, psychological distress, mood symptoms, or personality traits were included as potential mediators.

Methods: Data came from a follow-up visit $(N=115)$, carried out in 2016/2017, of a randomized controlled lifestyle intervention trial in 577 obese infertile women. The associations between total adversity exposure score and cardiometabolic health were tested with regression models. Sleep, smoking and eating behavior, symptoms of depression, anxiety and stress, and personality traits were potential mediators.
\end{abstract}

Results: Childhood adversity scores were not associated with cardiometabolic outcomes but were associated with poorer sleep quality score $(M=7.2$ ( $S D=3.5)$ for those with $\geq 2$ types of events versus 4.8 (2.9) for those with no events; $p=0.022$ ), higher external eating score (26.4 (8.7) versus $21.8(10.3) ; p=0.038)$, higher perceived stress score (17.1 (6.8) versus $12.3(4.5) ; p=0.016)$, post-traumatic stress score (1.9 (1.5) versus $0.6(1.1) ; p<0.001)$, and lower agreeableness score (28.2 (4.2) versus $30.3(3.1) ; p=0.035)$.

Conclusion: Childhood adversity was associated with poorer health behaviors including sleep and eating behavior, and more stress-related symptoms, but not with women's cardiometabolic health.

Keywords: Childhood adversity, Cardiometabolic health, Health behaviors, Personality, Mental wellbeing

\section{Background}

Childhood is an important developmental period during which exposure to adverse interpersonal or environmental events can meaningfully impact several domains of development and health $[1,2]$. Childhood adversity is relatively common, such that in high-income countries the prevalence of having experienced at least one

\footnotetext{
* Correspondence: lotte@iastate.edu

${ }^{1}$ Department of Human Development and Family Studies, lowa State University, Ames, lowa, USA

${ }^{2}$ Departments of Obstetrics and Gynaecology, University of Groningen, University Medical Center Groningen, Groningen, The Netherlands Full list of author information is available at the end of the article
}

adverse event during childhood was estimated to be almost $40 \%$ by the WHO World Mental Health Survey [3]. More recently, in the U.S., the prevalence of exposure to violence, crime or abuse in children and youth was estimated to be as high as 58\% [4]. Childhood adversity has negative effects on psychosocial and physical development $[2,5]$. For example, people who experienced childhood adversity are more likely to be overweight or obese [6], have higher blood pressures [7], and an increased risk of type 2 diabetes in adulthood [8]. There are indications of increased risks of cancer and premature mortality too $[2,9-11]$.

(c) The Author(s). 2019 Open Access This article is distributed under the terms of the Creative Commons Attribution 4.0 International License (http://creativecommons.org/licenses/by/4.0/), which permits unrestricted use, distribution, and reproduction in any medium, provided you give appropriate credit to the original author(s) and the source, provide a link to the Creative Commons license, and indicate if changes were made. The Creative Commons Public Domain Dedication waiver (http://creativecommons.org/publicdomain/zero/1.0/) applies to the data made available in this article, unless otherwise stated. 
Childhood adversity can come in the form of a broad array of types of events. These include witnessing a natural disaster, severe accidents, suffering from severe illness, or the death of someone close. However, being a victim of interpersonal trauma, including child abuse and sexual abuse, is more likely to result in mental health problems than other types of events [12]. It is not clear whether this association is also stronger for physical health outcomes.

Childhood adversity may directly impact cardiometabolic health. A large body of evidence suggests a direct effect of early life conditions on later development and health. The developmental origins of health and disease hypothesis [13] states that environmental stressors in early life during critical periods of development affect health and disease, such as increasing the risks of cardiovascular disease and mortality [14], through alterations in the body's physiology, immune and vascular functioning, increased levels of stress hormones, and higher rates of glucose intolerance $[1,7,13,15]$.

Besides a possible direct effect, childhood adversity may impact cardiometabolic health in an indirect manner. For example, childhood adversity has been linked with several negative health behaviors in adulthood, such as poor sleep quality [16], smoking [17] and an unhealthy diet [6], which are known to increase the risk of cardiometabolic diseases [18-20]. This suggests the association between childhood adversity and poor cardiometabolic health may be at least partially mediated by adverse health behaviors [21].

Psychological distress and mood symptoms are other potential mediators in the association between childhood adversity and poor cardiometabolic health [22]. Childhood adversity has been associated with high levels of perceived stress later in life [23]. Depressive symptoms, anxiety symptoms $[24,25]$, and also early-onset psychiatric disorders like pre-school onset depression, attention-deficit disorder, oppositional defiant disorder, conduct disorder, post-traumatic stress disorder (PTSD), generalized anxiety disorder, and separation anxiety [26], each have been shown to occur more often after early life adversity, and these may increase the risk for heart disease [27-30]. Indeed, findings from a systematic review showed that psychological distress and mood symptoms partly mediate the association between childhood adversity and cardiometabolic outcomes [31].

Personality is another factor that could partially mediate the negative effects of childhood adversity on cardiometabolic health. People who have experienced childhood adversity have higher levels of neuroticism [32], and lower levels of conscientiousness and openness to experience [33]. People who have experienced childhood adversity more often have type D personality, which is a combination of social inhibition and negative affectivity [34]. Low conscientiousness and high neuroticism are linked to poorer physical health [35], and type D personality is a documented risk factor for cardiovascular morbidity and mortality [36]. Collectively, these findings point to the possibility of personality traits partially mediating the effects of early adversity on later cardiometabolic health. Indeed, there is some evidence for this. One longitudinal study demonstrated that the effect of childhood adversity on cardiometabolic health in adolescence was mediated by levels of positive personality traits, such that those who experienced greater early adversity had lower levels of positive traits [37].

Demographic characteristics may be important in childhood adversity research. For example, the prevalence of childhood adversity seems to differ among racial/ethnic groups and is related to income disparities, such that Black and Hispanic children, as well as those from low-income families, are exposed to more adversity [38]. Compared to the U.S., income disparities in the Netherlands are small and there are fewer racial/ethnic minorities, and it is important to assess the impact of childhood adversity on cardiometabolic health in countries with different racial and ethnic demographics and variations in income gaps [39]. Furthermore, the association between childhood adversity and cardiometabolic health was shown to be more pronounced in women [40], indicating that there might be sex-specific effects that merit deeper focus on female samples.

From a prevention point of view, the investigation of potential indirect effects of childhood adversity on cardiometabolic health may provide insight into potential intermediate targets for intervention, if prevention of the adversity is not possible. This could result in better cardiometabolic health outcomes in the long-term for people who have experienced childhood adversity.

In the current study, using a Dutch sample of overweight and obese women of reproductive age, we examined whether childhood adversity (as a total score, but also interpersonal victimization specifically) was associated with poorer cardiometabolic health in adulthood. We also examined whether the association between childhood adversity and later cardiometabolic health was mediated by adverse health behaviors, psychological distress, mood symptoms, or specific personality traits.

\section{Methods}

In the original randomized controlled trial (RCT), carried out in the Netherlands, 577 obese infertile women were allocated to either a six-month lifestyle intervention or a control group. Women were eligible for participation in the RCT if they were between 18 and 39 years of age, had a body mass index (BMI) of $\geq 29 \mathrm{~kg} / \mathrm{m}^{2}$, and were infertile. Women with severe endometriosis, premature ovarian insufficiency, endocrinopathy, untreated preexisting hypertension, or women with a history of 
hypertension related pregnancy complications were not eligible for participation. The RCT was carried out in 23 hospitals and resulted in 822 women who were eligible for participation, 245 of these women decided not to participate, leaving 577 women who provided written informed consent. At the time of randomization, women were approximately 30 years old, had a mean weight of $103 \mathrm{~kg}$ and a mean BMI of $36 \mathrm{~kg} / \mathrm{m}^{2}$ (range $=29-51$ ). Results of the primary and secondary outcomes of this trial have been published previously $[41,42]$ and demonstrated that rates of a vaginal birth of a healthy singleton at 37 weeks or more were not higher in the intervention group, compared to the control group. The lifestyle intervention did lead to weight loss and improved cardiometabolic health in the short-term. The study was conducted following the principles of the Declaration of Helsinki, approved by the medical ethics committee of the University Medical Centre Groningen (METc code: 2008/284) and all participants gave written informed consent.

\section{Questionnaires}

The follow-up visit of the RCT was carried out between 3 and 8 years ( mean $=5$ years) after baseline assessments. The protocol of the follow-up visit has been published [43]. In short, between July 2016 and September 2017, a total of 115 women who participated in the follow-up visit filled out questionnaires regarding personality, physical health, psychological distress, mood symptoms, and life events. To evaluate adversity exposure during childhood and adolescence, the 17-item Life Events Checklist for DSM-5 (LEC-5) [44] was used. This questionnaire was slightly modified to be able to distinguish childhood adversity (between birth and 18 years of age); for events that a person experienced or witnessed, the year in which the event took place was asked and later used to calculate age at exposure. We calculated two total scores. The first score was a total adversity exposure score with all items summed (if a woman reported any type of event occurring once or more before the age of 19, she received a score of one for experiencing that type of event during childhood). Based on these scores, participants were then divided into three categories: a group that did not experience any type of event; a group that experienced one type of event; and a group that experienced two or more types of events. To be able to conduct sensitivity analyses to ascertain whether associations were stronger for interpersonal victimizationevents, a second score, interpersonal victimization, was calculated. This score included physical assault, sexual assault, and unwanted or uncomfortable sexual experiences, based on previous research indicating the greater relative impact of these type of events on health [12]. This variable was scored dichotomously, such that if a woman experienced this type of event at any point during childhood she received a score of one, and if she never experienced these events she received a score of zero. Thus, a dichotomous interpersonal victimization score reflected physical and sexual assault directly experienced by the individual during childhood, and the 3point total adversity score included those experiences as well as events that occurred more broadly in the woman's environment during childhood.

Health behaviors were assessed across three domains. Sleep quality was measured using the Pittsburg Sleep Quality Index (PSQI), a 19-item questionnaire that has been shown to have good internal consistency (Cronbach's alpha $(\alpha)=0.83)$ [45]. Smoking behavior was assessed via one item "Are you a current smoker?" (yes or no). To assess eating behavior, the Dutch Eating Behavior Questionnaire (DEBQ) was used, which resulted in three scores: external eating, restrained eating and emotional eating [46]. External eating reflects the sensitivity to external food cues, like the presence of food or taste, restrained eating reflects dieting attitudes and behaviors, and emotional eating reflects eating as coping mechanism to handle negative emotions. The DEBQ has demonstrated high internal consistency and subscale validity [46].

Psychological distress and mood symptoms were assessed with three questionnaires. Symptoms of anxiety and depression were assessed with the 14-item Hospital Anxiety and Depression Scale (HADS), resulting in summed anxiety and depression scores, with previous reports of good reliability $(\alpha$ depression $=0.82$; $\alpha$ anxiety $=$ $0.83)[47,48]$. The primary care PTSD screen (PC-PTSD), a short 5-item questionnaire with a total summed score, was used to screen for symptoms of post-traumatic stress disorder (PTSD) [49]. This questionnaire has demonstrated excellent diagnostic accuracy [49]. Perceived stress was measured with the 10-item summed Perceived Stress Scale (PSS), a questionnaire that has demonstrated excellent reliability $(\alpha=0.89)[50,51]$.

Personality was measured with two scales. The Big Five Inventory (BFI), a 44-item questionnaire, measures five dimensions of personality: extraversion, agreeableness, conscientiousness, neuroticism and openness [52], with previous reported reliability ranging from $\alpha=0.73$ to 0.86 [53]. The Type D Scale (DS-14), a 14-item questionnaire, measures type-D personality [54] and also has demonstrated good overall reliability previously, $\alpha=0.87$ [54]. The two components of type-D personality also demonstrated good reliability in previous research; social inhibition $(\alpha=0.86)$ and negative affectivity $(\alpha=0.88)$.

\section{Physical examination to assess cardiometabolic health}

Physical examinations were performed by trained research staff in a mobile research vehicle, parked near the participant's house. Height, weight, waist- and hip-circumference 
were each measured twice, and a third time if there was a large difference $(>0.5 \mathrm{~kg}$ for weight, $>0.5 \mathrm{~cm}$ for height and $>1 \mathrm{~cm}$ for waist- and hip-circumference) between the first two measurements. After a five-minute resting period, seated blood pressure was measured three times. Fasting blood samples were drawn by trained nurses, and the biochemical analyses were performed by the AMC Clinical Chemistry Laboratory. From the fasting blood samples, continuous levels of glucose, triglycerides, highdensity lipoprotein cholesterol (HDL-C) were obtained.

To assess the presence of metabolic syndrome, a reflection of composite cardiometabolic health, cut-off values for obesity, hyperglycemia, dyslipidemia (HDL-C and triglycerides) and hypertension were calculated based on the US National Cholesterol Education Program Adult Treatment Panel III (NCEP ATP III) criteria [55]. A positive classification of metabolic syndrome was based on having three or more elements either above the cut-off values, or based on pharmacological treatment for hyperglycemia, dyslipidemia or hypertension.

\section{Statistical analysis}

Demographic characteristics were examined with ANOVA or chi-square tests. A model with the visual representation of the associations tested is shown in Fig. 1, including the specific paths described below. ANOVA models and chisquare tests were used to test the difference in cardiometabolic health outcomes (individual measures and the composite classification score) between the groups with zero, one or $\geq 2$ different types of childhood adversity, and in the sensitivity analysis between the groups with and without interpersonal victimization (path C). Second, the associations between childhood adversity levels and potential mediators (personality traits, psychological distress, mood symptoms and health behavior variables) were tested using ANOVA models and Tukey post-hoc tests (path A).
The third set of analyses utilized a univariate (logistic) regression model examining the association between the mediators (personality, psychological distress, mood symptoms and health behavior) and the composite and individual cardiometabolic health outcomes (path B). To adjust for the possibility that intervention status affected the association of interest, sensitivity analyses were run that included the covariate representing randomization group in all models. All statistical analyses were performed using IBM SPSS version 24.0 (Armonk, NY, USA).

\section{Results}

Types of adverse events and participant characteristics

The adversity exposure groups and interpersonal victimization groups were similar in demographic characteristics (Table 1). In our sample, $n=69(57.4 \%)$ reported no childhood adverse events, $n=29(25.2 \%)$ reported 1 type of childhood adverse event, and $n=17$ (14.8\%) reported $\geq 2$ types of adverse events in childhood (with $n=7$ (6.1\%) reporting $\geq 3$ types of events). The most commonly reported adverse event was a transportation accident $(n=$ 18) including car, boat, train and plane accidents, followed by physical assault $(n=11)$, sexual assault $(n=8)$, unwanted sexual experiences $(n=8)$, life threatening illness/ injury $(n=7)$, severe illness or injury $(n=6)$ and sudden unexpected death of someone close $(n=6)$.

\section{Associations between childhood adversity and cardiometabolic health}

No differences were observed in cardiometabolic health outcomes between women without adversity or women with one or two or more types of adverse childhood events (Table 2). No group differences were observed in the sensitivity analyses testing the association between interpersonal victimization and cardiometabolic health either.

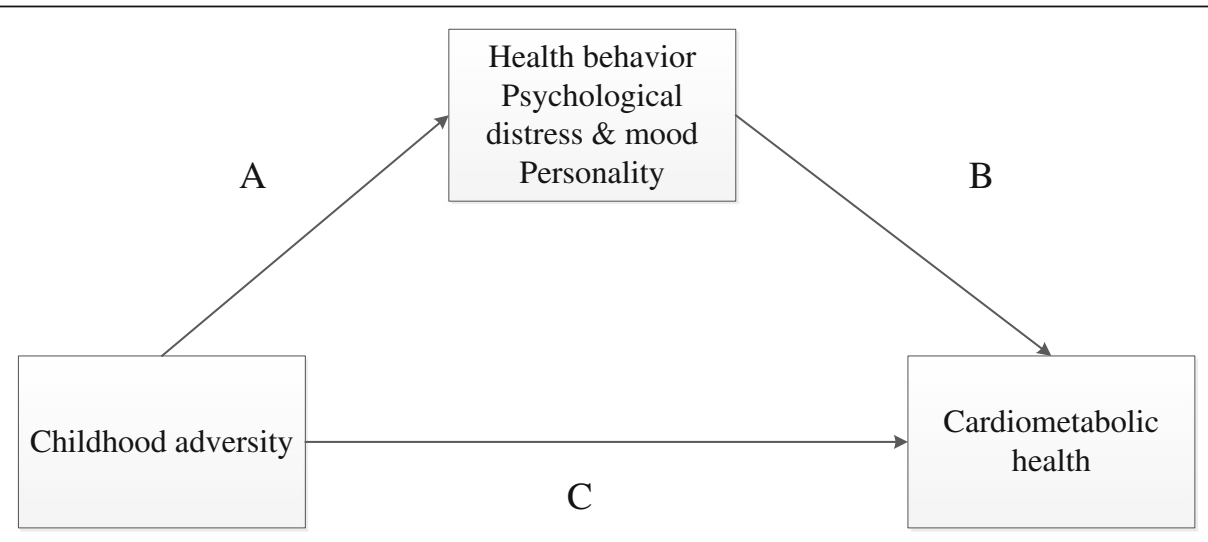

Fig. 1 Visual model with the hypothesized main effect and mediation effects. Note: The mediators in this model include health behavior (sleep quality, smoking behavior and external, restrained, and emotional eating behavior), psychological distress and mood symptoms (symptoms of depression, anxiety, perceived stress and post-traumatic stress symptoms), and personality (openness, conscientiousness, extraversion, agreeableness, neuroticism and type D personality) 
Table 1 Characteristics of the study participants

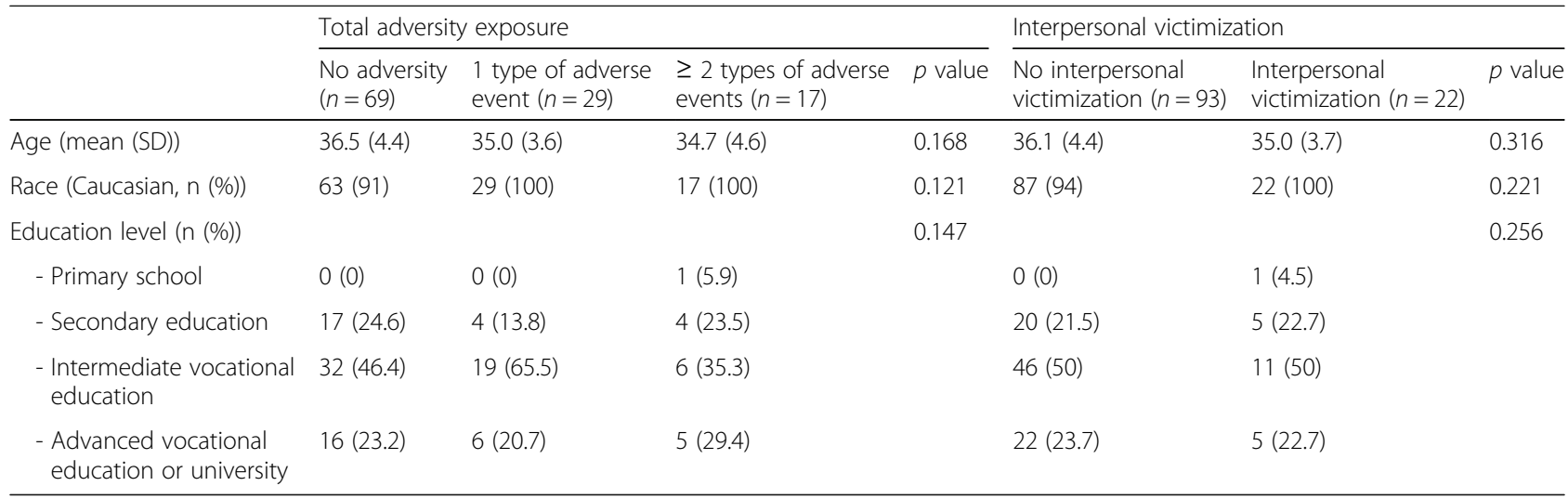

\section{Associations between childhood adversity and potential mediators \\ Total adversity score}

Sleep quality scores were higher, reflecting worse sleep quality, in women with $\geq 2$ types of childhood adverse events (7.2 (3.5)), compared to women without adversity (4.8 (2.9); $p=0.022)$. Also, higher external eating scores were observed in women with 1 type of childhood adverse event $(26.4(8.7))$, compared to women without adversity (21.8 (10.3); $p=0.038)$. No differences were observed for symptoms of depression and anxiety between the groups. Levels of perceived stress were significantly higher among women with $\geq 2$ types of childhood adverse events (17.1 (6.8)), compared to women with 1 type of childhood adverse event (12.3 (4.5); $p=0.016)$. Furthermore, higher rates of PTSD symptoms were found in women with $\geq 2$ types of childhood adverse events $(1.9(1.5))$, compared to women without adversity (0.6 (1.1); $p<0.001)$. For agreeableness, a significantly lower score was found in women with 1 type of adverse event (28.2 (4.2)), compared to the group without adverse events (30.1 (3.1); $p=0.035)$ (Table 3).

\section{Interpersonal adversity}

The sensitivity analyses focused on exposure to interpersonal victimization during childhood paralleled the associations observed for the total adversity score described above. In addition to those associations, women with childhood interpersonal victimization were more often smokers $(n=7(31.8 \%) ; p=0.048)$ than those without interpersonal victimization $(n=9(10.7 \%))$. A positive score on the type $\mathrm{D}$ personality subscale negative affectivity was more prevalent in women with childhood interpersonal victimization $(n=16(72.7 \%))$, compared to those without $(n=42(45.2 \%) ; p=0.020)$. Women with interpersonal victimization reported lower conscientiousness (26.6 (4.3)), compared to women without interpersonal victimization $(28.7(3.9) ; p=0.030)$.

\section{Associations between potential mediators and cardiometabolic health}

No statistically significant associations were observed for path $\mathrm{B}$ between health behaviors and cardiometabolic health outcomes (shown in Table 4) or between psychological distress, mood symptoms, personality and cardiometabolic

Table 2 Childhood adversity and cardiometabolic health outcomes (path C)

\begin{tabular}{|c|c|c|c|c|c|c|c|}
\hline & \multicolumn{4}{|c|}{ Total adversity exposure } & \multicolumn{3}{|c|}{ Interpersonal victimization } \\
\hline & $\begin{array}{l}\text { No adversity } \\
(n=69)\end{array}$ & $\begin{array}{l}1 \text { type of adverse } \\
\text { event }(n=29)\end{array}$ & $\begin{array}{l}\geq 2 \text { types of adverse } \\
\text { events }(n=17)\end{array}$ & $p$ value & $\begin{array}{l}\text { No interpersonal } \\
\text { victimization }(n=93)\end{array}$ & $\begin{array}{l}\text { Interpersonal } \\
\text { victimization }(n=22)\end{array}$ & $p$ value \\
\hline \multicolumn{8}{|l|}{ Anthropometrics } \\
\hline BMI & $35.7(5.2)$ & $34.7(4.5)$ & $36.2(6.7)$ & 0.593 & $35.7(5.1)$ & $34.7(6.1)$ & 0.437 \\
\hline Waist circumference (cm) & $106.8(11.2)$ & $103.5(10.2)$ & $107.4(13.5)$ & 0.396 & $106.7(11.5)$ & $103.1(10.3)$ & 0.197 \\
\hline \multicolumn{8}{|l|}{ Blood pressure } \\
\hline $\mathrm{SBP}(\mathrm{mmHg})$ & $120.6(14.4)$ & $118.6(13.5)$ & $122.9(16.2)$ & 0.628 & $120.5(14.5)$ & $120.3(14.2)$ & 0.962 \\
\hline $\mathrm{DBP}(\mathrm{mmHg})$ & $81.9(10.1)$ & 80.9 (8.8) & $82.1(8.8)$ & 0.872 & $81.8(9.8)$ & $81.1(8.5)$ & 0.747 \\
\hline \multicolumn{8}{|l|}{ Composite outcome } \\
\hline Metabolic syndrome & $25(41.7 \%)$ & $9(36.0 \%)$ & 7 (46.7\%) & 0.791 & $34(41.0 \%)$ & $7(41.2 \%)$ & 0.987 \\
\hline
\end{tabular}

Results are presented as mean (standard deviation (SD)) or prevalence (percentage) $B M I$ body mass index, SBP systolic blood pressure, DBP diastolic blood pressure 
Table 3 Childhood adversity and health behavior, psychological distress, mood symptoms and personality (path A)

\begin{tabular}{|c|c|c|c|c|c|c|c|}
\hline & \multicolumn{4}{|c|}{ Total adversity exposure } & \multicolumn{3}{|c|}{ Interpersonal victimization } \\
\hline & $\begin{array}{l}\text { No adversity } \\
(n=69)\end{array}$ & $\begin{array}{l}1 \text { type of adverse } \\
\text { event }(n=29)\end{array}$ & $\begin{array}{l}\geq 2 \text { types of adverse } \\
\text { events }(n=17)\end{array}$ & $p$ value & $\begin{array}{l}\text { No interpersonal } \\
\text { victimization }(n=93)\end{array}$ & $\begin{array}{l}\text { Interpersonal } \\
\text { victimization }(n=22)\end{array}$ & $\overline{p \text { value }}$ \\
\hline \multicolumn{8}{|l|}{ Health behavior } \\
\hline Sleep quality & $4.8(2.9)$ & $5.6(3.6)$ & $7.2(3.5)$ & 0.026 & $5.0(3.2)$ & $6.8(3.3)$ & 0.027 \\
\hline Current smoker & $7(11.3 \%)$ & $5(18.5 \%)$ & $4(23.5 \%)$ & 0.658 & $9(10.7 \%)$ & $7(31.8 \%)$ & 0.048 \\
\hline External eating score & $21.8(10.3)$ & $26.4(8.7)$ & $26.3(3.5)$ & 0.038 & $22.6(10.0)$ & $28.2(4.3)$ & 0.011 \\
\hline Restrained eating score & $23.4(10.8)$ & $24.6(8.6)$ & $28.1(7.3)$ & 0.208 & $24.0(10.4)$ & $26.0(7.6)$ & 0.391 \\
\hline Emotional eating score & $26.0(14.3)$ & $31.0(12.3)$ & $30.0(10.0)$ & 0.183 & $26.8(13.8)$ & $32.1(10.0)$ & 0.096 \\
\hline \multicolumn{8}{|c|}{ Psychological distress and mood } \\
\hline Depression symptoms & $7.5(3.5)$ & $7.0(2.3)$ & $7.8(2.8)$ & 0.731 & $7.3(3.2)$ & $7.9(2.7)$ & 0.381 \\
\hline Anxiety symptoms & $7.6(3.1)$ & $8.5(3.8)$ & $8.9(2.9)$ & 0.285 & $7.9(3.2)$ & $8.8(3.5)$ & 0.266 \\
\hline Perceived stress & $14.0(5.7)$ & $12.3(4.5)$ & $17.1(6.8)$ & 0.022 & $13.7(5.5)$ & $15.5(6.6)$ & 0.166 \\
\hline PTSD symptoms & $0.6(1.1)$ & $0.5(1.1)$ & $1.9(1.5)$ & $<0.0001$ & $0.7(1.1)$ & $1.2(1.5)$ & 0.063 \\
\hline \multicolumn{8}{|l|}{ Personality } \\
\hline Type D personality & $14(20.3 \%)$ & $7(24.1 \%)$ & $8(47.1 \%)$ & 0.074 & $20(21.5 \%)$ & $9(40.9 \%)$ & 0.059 \\
\hline Social inhibition & $25(36.2 \%)$ & $13(44.8 \%)$ & $8(47.1 \%)$ & 0.594 & $36(38.7 \%)$ & $10(45.5 \%)$ & 0.561 \\
\hline Negative affectivity & $31(44.9 \%)$ & $15(51.7 \%)$ & $12(70.6 \%)$ & 0.164 & $42(45.2 \%)$ & $16(72.7 \%)$ & 0.020 \\
\hline Openness & $32.4(5.6)$ & $33.4(4.0)$ & $34.4(3.7)$ & 0.319 & $32.9(5.3)$ & $33.5(3.4)$ & 0.636 \\
\hline Conscientiousness & $28.8(4.1)$ & $27.7(4.1)$ & $27.6(3.8)$ & 0.394 & $28.7(3.9)$ & $26.6(4.3)$ & 0.030 \\
\hline Extraversion & $25.1(5.4)$ & $24.9(4.2)$ & $24.9(4.1)$ & 0.989 & $24.9(5.1)$ & $25.3(4.0)$ & 0.722 \\
\hline Agreeableness & $30.1(3.1)$ & $28.2(4.2)$ & $30.4(3.9)$ & 0.034 & $30.0(3.4)$ & $29.1(4.7)$ & 0.318 \\
\hline Neuroticism & $22.3(5.9)$ & $24.7(3.7)$ & $24.5(4.7)$ & 0.091 & $22.8(5.4)$ & $25.1(4.5)$ & 0.069 \\
\hline
\end{tabular}

Results are presented as mean (SD) or prevalence (percentage)

PTSD post-traumatic stress disorder

health (shown in Tables 5 and 6). Repeating the analyses with intervention randomization group as a covariate did not change the results presented in Tables 2, 3, 4, 5 and 6 . Due to the lack of associations between childhood adversity and cardiometabolic health variables, no formal tests of mediation were conducted.

\section{Discussion}

Within an understudied population of overweight and obese Dutch women of reproductive age, the present study provides evidence that childhood adversity is associated with poorer health behaviors, including sleep quality and eating behavior, and more stress-related symptoms in adulthood. However, childhood adversity was not associated with cardiometabolic health outcomes in these women.

The associations we observed between childhood adversity and various indices of health behaviors, psychological distress, and personality are in line with previous research. As in other studies, we found a higher prevalence of

Table 4 Health behaviors and cardiometabolic health outcomes (path B)

\begin{tabular}{|c|c|c|c|c|c|}
\hline & Sleep quality & Smoking status & External eating score & Restrained eating score & Emotional eating score \\
\hline \multicolumn{6}{|l|}{ Anthropometrics } \\
\hline BMI & $-0.101(0.192)$ & $0.516(0.701)$ & $-0.030(0.061)$ & $-0.074(0.057)$ & $-0.009(0.044)$ \\
\hline Waist circumference $(\mathrm{cm})$ & $-0.236(0.418)$ & $0.962(1.538)$ & $-0.092(0.134)$ & $-0.189(0.125)$ & $-0.064(0.096)$ \\
\hline \multicolumn{6}{|l|}{ Blood pressure } \\
\hline $\mathrm{SBP}(\mathrm{mmHg})$ & $0.465(0.473)$ & $-1.701(1.851)$ & $-0.086(0.166)$ & $-0.052(0.156)$ & $-0.084(0.119)$ \\
\hline $\mathrm{DBP}(\mathrm{mmHg})$ & $0.140(0.318)$ & $-1.179(1.184)$ & $-0.049(0.112)$ & $-0.082(0.105)$ & $-0.066(0.080)$ \\
\hline \multicolumn{6}{|l|}{ Composite outcome } \\
\hline Metabolic syndrome & $\mathrm{OR}=1.116$ & $\mathrm{OR}=0.836$ & $\mathrm{OR}=1.002$ & $\mathrm{OR}=0.973$ & $\mathrm{OR}=1.002$ \\
\hline
\end{tabular}

Results are presented as regression coefficient(standard error(SE)) or odds ratio (OR) $B M I$ body mass index, SBP systolic blood pressure, DBP diastolic blood pressure 
Table 5 Psychological distress, mood symptoms and cardiometabolic health (path B)

\begin{tabular}{|c|c|c|c|c|}
\hline & Depression symptoms & Anxiety symptoms & Perceived stress & PTSD symptoms \\
\hline \multicolumn{5}{|l|}{ Anthropometrics } \\
\hline BMI & $0.185(0.187)$ & $-0.040(0.180)$ & $-0.084(0.103)$ & $-0.463(0.499)$ \\
\hline Waist circumference (cm) & $0.369(0.413)$ & $-0.279(0.396)$ & $-0.293(0.224)$ & $-0.712(1.095)$ \\
\hline \multicolumn{5}{|l|}{ Blood pressure } \\
\hline $\mathrm{SBP}(\mathrm{mmHg})$ & $-0.175(0.485)$ & $0.323(0.463)$ & $0.244(0.279)$ & $2.048(1.281)$ \\
\hline $\mathrm{DBP}(\mathrm{mmHg})$ & $-0.095(0.312)$ & $0.481(0.293)$ & $-0.009(0.188)$ & $0.378(0.867)$ \\
\hline \multicolumn{5}{|l|}{ Composite outcome } \\
\hline Metabolic syndrome & $\mathrm{OR}=1.122$ & $\mathrm{OR}=1.078$ & $\mathrm{OR}=0.982$ & $\mathrm{OR}=1.034$ \\
\hline
\end{tabular}

Results are presented as regression coefficient(SE) or odds ratio (OR)

PTSD post-traumatic stress disorder, BMI body mass index, SBP systolic blood pressure, DBP diastolic blood pressure

smoking [17], a higher prevalence of negative affectivity, one of the subscales of type D personality [34], and lower levels of conscientiousness [32, 33] among those who experienced interpersonal victimization during childhood. The associations between childhood adversity and higher levels of perceived stress and PTSD symptoms are also in line with previous research $([23,26])$, as are the associations between childhood adversity and lower sleep quality [16] and unhealthy eating behavior [6]. We found a positive association between childhood adversity and external eating behavior, where external factors, like the presence of food or the smell of food, lead to more eating [46], which is a finding not previously observed, to our knowledge. This suggests that childhood adversity may lead to more external eating behavior, which is linked to increased rates of overweight and obesity [56].

We observed associations in the analyses with childhood interpersonal victimization that were not observed in the analyses with total childhood adversity exposure. Women who had experienced interpersonal victimization were more often smokers, had more often negative affect and lower scores on conscientiousness. The observation regarding smoking behavior is in line with previous work, suggesting that interpersonal victimization affects health behavior more than other types of childhood adversity [12]. The association between childhood interpersonal victimization and personality traits (negative affect and lower conscientiousness) in adulthood has not been described previously for childhood interpersonal victimization specifically. These results suggest childhood interpersonal victimization is linked to a personality characterized by experiencing negative emotions, having less self-discipline and being less goal-oriented. Prior research suggests that these personality traits may lead to increased rates of cardiovascular disease [36, 57].

The results described in this paper regarding associations with cardiometabolic health outcomes contrast those of a large body of existing literature demonstrating the detrimental effects of childhood adversity on cardiometabolic health, cardiovascular disease and mortality [6-9]. The discrepancy between previous findings and those in the current study may be due to a number of factors. First, the types and severity of childhood adverse events reported in our sample are less severe than the types of adverse events described in the existing literature [9]. The most common adverse event reported in our study was a transportation accident, while the literature suggests that more severe events, like childhood abuse, are associated with long-term health effects [58]. However, the sensitivity analyses conducted with interpersonal victimization as a measure of those more severe events also did not reveal associations with cardiometabolic

Table 6 Personality and cardiometabolic health (path B)

\begin{tabular}{|c|c|c|c|c|c|c|}
\hline & Type D personality & Openness & Conscientiousness & Extraversion & Agreeableness & Neuroticism \\
\hline \multicolumn{7}{|l|}{ Anthropometrics } \\
\hline BMI & $-0.668(1.158)$ & $-0.012(0.124)$ & $-0.143(0.150)$ & $0.032(0.132)$ & $0.132(0.175)$ & $-0.149(0.114)$ \\
\hline Waist circumference $(\mathrm{cm})$ & $-1.478(2.490)$ & $0.075(0.272)$ & $-0.009(0.333)$ & $0.111(0.290)$ & $0.183(0.386)$ & $-0.392(0.250)$ \\
\hline \multicolumn{7}{|l|}{ Blood pressure } \\
\hline $\mathrm{SBP}(\mathrm{mmHg})$ & $-3.987(3.140)$ & $0.221(0.319)$ & $0.183(0.391)$ & $0.153(0.341)$ & $0.373(0.453)$ & $-0.123(0.298)$ \\
\hline $\mathrm{DBP}(\mathrm{mmHg})$ & $-3.358(2.065)$ & $0.296(0.202)$ & $0.007(0.251)$ & $0.106(0.218)$ & $0.084(0.291)$ & $0.070(0.191)$ \\
\hline \multicolumn{7}{|l|}{ Composite outcome } \\
\hline Metabolic syndrome & $\mathrm{OR}=1.214$ & $\mathrm{OR}=1.032$ & $\mathrm{OR}=0.931$ & $\mathrm{OR}=0.990$ & $\mathrm{OR}=1.007$ & $\mathrm{OR}=1.026$ \\
\hline
\end{tabular}

Results are presented as regression coefficient(SE) or odds ratio (OR) 
health in our sample. In addition to the apparent difference in type of events, there appeared to be a difference in the number of people exposed to several severe childhood adverse events, which was uncommon in our sample $(6 \%$ had experienced $\geq 3$ types of events). A dose-response relationship between childhood adversity and cardiometabolic health has been suggested previously, indicating that exposure to several childhood adversities is associated with poorer cardiometabolic health [9]. The small number of women with exposure to several severe childhood adverse events in our sample precluded a dose-response type of analysis. That said, it was important to discern whether the level of childhood adversity experienced by women in this understudied population played a role in the development of health behaviors, psychological distress, mood symptoms and personality to inform prevention efforts to target these risk factors for cardiometabolic disease.

Another difference between the existing literature examining the association between childhood adversity and cardiometabolic health outcomes and our study is the age of the sample. Our sample consisted of obese women who sought infertility treatment several years prior, whereas other studies conducted analyses among a general population, including predominantly people of older age $[7,9$, 10]. The harmful effects of childhood adversity, partially occurring through unhealthy behaviors, psychological distress, mood symptoms and personality traits, on metabolic health and cardiovascular disease may take more time to develop. Even in at-risk populations, women are protected against cardiovascular disease before menopause, as a result of the atheroprotective effects of estrogen $[59,60]$. If our study population is followed until after menopause, the effects of childhood adversity on metabolic and cardiovascular disease may be more similar to those found in previous research.

Limitations of this study should be noted. Our results may not be generalizable to a population that includes men. For example, sex-specific findings suggest that men are less vulnerable to the effects of childhood adversity on cardiovascular disease [40]. In addition, the data regarding childhood adversity were collected retrospectively in adulthood, which might have led to recall bias. Individuals experiencing stress or symptoms of depression may be more likely to report childhood adversity, which may lead to overestimating the impact of childhood adversity on the outcomes [59]. Although shorter time intervals between the event and the moment of recall are ideal, it has been suggested that reports of childhood adversity are stable over time and reliable [61]. Limitations notwithstanding, this work contributes to the literature by giving insight in the association between childhood adversity and health behaviors, psychological distress, mood symptoms and personality in an understudied population.

\section{Conclusion}

We found that childhood adversity was associated with poorer health behaviors and greater reports of perceived stress and post-traumatic stress symptoms in adulthood. In our sample of overweight and obese women of reproductive age, no association was observed between childhood adversity and cardiometabolic health outcomes. The adverse health behaviors and increased symptoms of stress in women who experienced childhood adversity may induce poorer cardiometabolic health outcomes in the future though, warranting further follow-up of this group.

\section{Abbreviations \\ BFI: Big five inventory; BMl: Body mass index; DEBQ: Dutch eating behavior questionnaire; DS-14: Type D scale; HADS: Hospital anxiety and depression scale; HDL-C: High-density lipoprotein cholesterol; LEC-5: Life events checklist for DSM-5; PC-PTSD: Primary care - post-traumatic stress disorder; PSQI: Pittsburg sleep quality index; PSS: Perceived stress scale; PTSD: Post- traumatic stress disorder; RCT: Randomized controlled trial}

\section{Acknowledgements}

We thank all women who participated in the LIFEstyle study and the follow-up visit. We thank all students, PhD students, research nurses, and other research personnel involved in the LIFEstyle study and follow-up visit.

\section{Authors' contributions}

$L v D, N B, S d R, B W M, H G, A H$, and TR have been responsible for the idea and the design of the study. LVD and NB drafted the manuscript and performed the analyses. All authors revised the manuscript and had critical discussions of the manuscript. All authors have approved the final version of the manuscript.

\section{Funding}

This research was supported by The Netherlands Organization for Health Research and Development (50-50110-96-518), the Dutch Heart Foundation (Grant number: 2013 T085), and the European Commission (Horizon2020 project 'DynaHealth', 633595). The department of obstetrics and gynaecology from the UMCG received an unrestricted educational grant from Ferring Pharmaceutical BV the Netherlands, unrelated to the present study.

\section{Availability of data and materials}

A minimal dataset is available upon request.

Ethics approval and consent to participate

The study was conducted following the principles of the Declaration of Helsinki, approved by the medical ethics committee of the University Medical Centre Groningen (METc code: 2008/284) and all participants gave written informed consent.

\section{Consent for publication}

Not applicable.

\section{Competing interests}

The authors declare that they have no competing interests.

\section{Author details}

${ }^{1}$ Department of Human Development and Family Studies, lowa State University, Ames, lowa, USA. Departments of Obstetrics and Gynaecology, University of Groningen, University Medical Center Groningen, Groningen, The Netherlands. ${ }^{3}$ Department of Epidemiology, University of Groningen, University Medical Center Groningen, Groningen, The Netherlands.

${ }^{4}$ Departments of Psychiatry and Pediatrics, University of California San Francisco, San Francisco, California, USA. ${ }^{5}$ Division of Developmental Medicine, Center for Health and Community, San Francisco, California, USA. ${ }^{6}$ Departments of Clinical Epidemiology, Biostatistics and Bioinformatics, Amsterdam UMC at the University of Amsterdam, Amsterdam, The Netherlands. ${ }^{7}$ Obstetrics and Gynaecology, Amsterdam UMC at the University of Amsterdam, Amsterdam, The Netherlands. ${ }^{8}$ Department of Obstetrics and Gynaecology, Monash University, Clayton, Victoria, Australia. 
Received: 11 April 2019 Accepted: 2 July 2019

Published online: 23 July 2019

\section{References}

1. Shonkoff JP, Garner AS, Siegel BS, Dobbins MI, Earls MF, Garner AS, McGuinn L, Pascoe J, Wood DL. The lifelong effects of early childhood adversity and toxic stress. Pediatrics. 2012;129(1):e232-46. https://doi.org/10.1542/peds.2 011-2663.

2. Wegman $\mathrm{HL}$, Stetler C. A meta-analytic review of the effects of childhood abuse on medical outcomes in adulthood. Psychosom Med. 2009;71(8):80512. https://doi.org/10.1097/PSY.0b013e3181bb2b46.

3. Kessler RC, McLaughlin KA, Green JG, Gruber MJ, Sampson NA, Zaslavsky AM, Aguilar-Gaxiola S, Alhamzawi AO, Alonso J, Angermeyer M, Benjet C, Bromet E, Chatterji S, de Girolamo G, Demyttenaere K, Fayyad J, Florescu S, Gal G, Gureje O, Haro JM, Hu CY, Karam EG, Kawakami N, Lee S, Lepine JP, Ormel J, Posada-Villa J, Sagar R, Tsang A, Ustun TB, Vassilev S, Viana MC, Williams DR. Childhood adversities and adult psychopathology in the WHO world mental health surveys. Br J Psychiatry. 2010;197(5):378-85. https://doi. org/10.1192/bjp.bp.110.080499.

4. Finkelhor D, Turner HA, Shattuck A, Hamby SL. Violence, crime, and abuse exposure in a national sample of children and youth: an update. JAMA Pediatr. 2013;167(7):614-21. https://doi.org/10.1001/jamapediatrics.2013.42.

5. Shonkoff JP, Boyce WT, McEwen BS. Neuroscience, molecular biology, and the childhood roots of health disparities: building a new framework for health promotion and disease prevention. Jama. 2009;301(21):2252-9. https://doi.org/10.1001/jama.2009.754

6. Isohookana R, Marttunen M, Hakko H, Riipinen P, Riala K. The impact of adverse childhood experiences on obesity and unhealthy weight control behaviors among adolescents. Compr Psychiatry. 2016;71:17-24. https://doi. org/10.1016/j.comppsych.2016.08.002.

7. Alastalo H, Raikkonen K, Pesonen AK, Osmond C, Barker DJ, Heinonen K, Kajantie E, Eriksson JG. Early life stress and blood pressure levels in late adulthood. J Hum Hypertens. 2013;27(2):90-4. https://doi.org/10.1038/ jhh.2012.6.

8. Huang H, Yan P, Shan Z, Chen S, Li M, Luo C, Gao H, Hao L, Liu L. Adverse childhood experiences and risk of type 2 diabetes: A systematic review and meta-analysis. Metabolism. 2015;64(11):1408-18. https://doi.org/10.1016/j. metabol.2015.08.019.

9. Appleton AA, Holdsworth E, Ryan M, Tracy M. Measuring childhood adversity in life course cardiovascular research: A systematic review. Psychosom Med. 2017;79(4):434-40. https://doi.org/10.1097/psy. 0000000000000430.

10. Bellis MA, Hughes K, Leckenby N, Hardcastle KA, Perkins C, Lowey $H$. Measuring mortality and the burden of adult disease associated with adverse childhood experiences in England: a national survey. J Public Health (Oxf). 2015;37(3):445-54. https://doi.org/10.1093/pubmed/fdu065.

11. Chen E, Turiano NA, Mroczek DK, Miller GE. Association of Reports of childhood abuse and all-cause mortality rates in women. JAMA Psychiatry. 2016;73(9):920-7. https://doi.org/10.1001/jamapsychiatry.2016.1786.

12. Mongan D, Shannon C, Hanna D, Boyd A, Mulholland C. The association between specific types of childhood adversity and attenuated psychotic symptoms in a community sample. Early Interv Psychiatry. 2017. https://doi. org/10.1111/eip.12478.

13. Barker DJ. Maternal nutrition, fetal nutrition, and disease in later life Nutrition. 1997;13(9):807-13.

14. Wilson PWF, D'Agostino RB, Levy D, Belanger AM, Silbershatz H, Kannel WB. Prediction of coronary heart disease using risk factor categories. Circulation. 1998;97(18):1837-47. https://doi.org/10.1161/01.Cir.97.18.1837.

15. Slopen N, Lewis TT, Gruenewald TL, Mujahid MS, Ryff CD, Albert MA, Williams DR. Early life adversity and inflammation in African Americans and whites in the midlife in the United States survey. Psychosom Med. 2010; 72(7):694-701. https://doi.org/10.1097/PSY.0b013e3181e9c16f.

16. Kajeepeta S, Gelaye B, Jackson CL, Williams MA. Adverse childhood experiences are associated with adult sleep disorders: a systematic review. Sleep Med. 2015;16(3):320-30. https://doi.org/10.1016/j.sleep.2014.12.013.

17. Anda RF, Croft JB, Felitti VJ, Nordenberg D, Giles WH, Williamson DF, Giovino GA. Adverse childhood experiences and smoking during adolescence and adulthood. Jama. 1999;282(17):1652-8.

18. Cappuccio FP, Cooper D, D'Elia L, Strazzullo P, Miller MA. Sleep duration predicts cardiovascular outcomes: a systematic review and meta-analysis of prospective studies. Eur Heart J. 2011;32(12):1484-92. https://doi.org/10.1 093/eurheartj/ehr007.

19. Ockene IS, Miller NH. Cigarette smoking, cardiovascular disease, and stroke. Circulation. 1997;96(9):3243.

20. Torres SJ, Nowson CA. Relationship between stress, eating behavior, and obesity. Nutrition. 2007;23(11):887-94. https://doi.org/10.1016/j.nut.2007.08.008.

21. Suglia SF, Koenen KC, Boynton-Jarrett R, Chan PS, Clark CJ, Danese A, Faith MS, Goldstein BI, Hayman LL, Isasi CR, Pratt CA, Slopen N, Sumner JA, Turer A, Turer CB, Zachariah JP. Childhood and adolescent adversity and Cardiometabolic outcomes: A scientific statement from the American Heart Association. Circulation. 2017. https://doi.org/10.1161/cir.0000000000000536.

22. Bush NR, Lane RD, McLaughlin KA. Mechanisms underlying the association between early-life adversity and physical health: charting a course for the future. Psychosom Med. 2016;78(9):1114-9. https://doi.org/10.1097/psy. 0000000000000421.

23. Anda RF, Butchart A, Felitti VJ, Brown DW. Building a Framework for Global Surveillance of the Public Health Implications of Adverse Childhood Experiences. Am J Prev Med. 2010;39(1):93-8. https://doi.org/10.1016/j. amepre.2010.03.015.

24. Luecken LJ, Jewell SL, MacKinnon DP. Prediction of postpartum weight in low-income Mexican-origin women from childhood experiences of abuse and family conflict. Psychosom Med. 2016;78(9):1104-13. https://doi.org/10.1 097/psy.0000000000000391.

25. Tomfohr-Madsen LM, Bayrampour H, Tough S. Maternal history of childhood abuse and risk of asthma and allergy in 2-year-old children. Psychosom Med. 2016;78(9):1031-42. https://doi.org/10.1097/psy. 0000000000000419 .

26. Whalen DJ, Belden AC, Tillman R, Barch DM, Luby JL. Early adversity, psychopathology, and latent class profiles of global physical health from preschool through early adolescence. Psychosom Med. 2016;78(9):1008-18. https://doi.org/10.1097/psy.0000000000000398.

27. Dedert EA, Calhoun PS, Watkins LL, Sherwood A, Beckham JC. Posttraumatic stress disorder, cardiovascular, and metabolic disease: a review of the evidence. Ann Behav Med. 2010;39(1):61-78. https://doi.org/10.1007/s12160010-9165-9.

28. Kinder LS, Carnethon MR, Palaniappan LP, King AC, Fortmann SP. Depression and the metabolic syndrome in young adults: findings from the third National Health and nutrition examination survey. Psychosom Med. 2004;66(3):316-22

29. Richardson S, Shaffer JA, Falzon L, Krupka D, Davidson KW, Edmondson D. Meta-analysis of perceived stress and its association with incident coronary heart disease. Am J Cardiol. 2012;110(12):1711-6. https://doi.org/10.1016/j. amjcard.2012.08.004.

30. Scott KM. Depression, anxiety and incident cardiometabolic diseases. Curr Opin Psychiatry. 2014;27(4):289-93. https://doi.org/10.1097/yco. 0000000000000067

31. Basu A, McLaughlin KA, Misra S, Koenen KC. Childhood maltreatment and health impact: the examples of cardiovascular disease and type 2 diabetes mellitus in adults. Clin Psychol (New York). 2017;24(2):125-39. https://doi. org/10.1111/cpsp.12191.

32. Wilson RS, Krueger KR, Arnold SE, Barnes LL. Mendes de Leon CF, Bienias JL, Bennett DA. Childhood adversity and psychosocial adjustment in old age. Am J Geriatr Psychiatry. 2006;14(4):307-15. https://doi.org/10.1097/01.JGP. 0000196637.95869.d9.

33. Fletcher, Jason M. and Schurer, Stefanie. 2017. "Origins of Adulthood Personality: The Role of Adverse Childhood Experiences." IZA Discussion Paper No. 10538. (Available at SSRN: https://ssrn.com/abstract=2911476).

34. Demirci K, Yildiz M, Selvi C, Akpinar A. The relationship between childhood trauma and type D personality in university students. Int J Soc Psychiatry. 2016;62(6):542-8. https://doi.org/10.1177/0020764016653774.

35. Friedman HS. Long-term relations of personality and health: dynamisms, mechanisms, tropisms. J Pers. 2000;68(6):1089-107.

36. Pedersen SS, Denollet J. Type D personality, cardiac events, and impaired quality of life: a review. Eur J Cardiovasc Prev Rehabil. 2003;10(4):241-8. https://doi.org/10.1097/01.hjr.0000085246.65733.06.

37. Wickrama KK, O'Neal CW, Lee TK, Wickrama T. Early socioeconomic adversity, youth positive development, and young adults' cardio-metabolic disease risk. Health Psychol. 2015;34(9):905-14. https://doi.org/10.1037/ hea0000208.

38. Slopen N, Shonkoff JP, Albert MA, Yoshikawa H, Jacobs A, Stoltz R, Williams DR. Racial disparities in child adversity in the U.S.: interactions with family 
immigration history and income. Am J Prev Med. 2016;50(1):47-56. https:// doi.org/10.1016/j.amepre.2015.06.013.

39. Netherlands, Statistics. 2014. "Statistics Netherlands: Income gaps stable and relatively small". https://www.cbs.nl/en-gb/news/2014/23/income-gapsstable-and-relatively-small.

40. Garad Y, Maximova K, MacKinnon N, McGrath JJ, Kozyrskyj AL, Colman I. Sex-specific differences in the association between childhood adversity and cardiovascular disease in adulthood: evidence from a National Cohort Study. Can J Cardiol. 2017;33(8):1013-9. https://doi.org/10.1016/j.cjca.2017.05.008.

41. Mutsaerts MAQ, van Oers AM, Groen H, Burggraaff JM, Kuchenbecker WKH, Perquin DAM, Koks CAM, van Golde R, Kaaijk EM, Schierbeek JM, Oosterhuis GJE, Broekmans FJ, Bemelmans WJE, Lambalk CB, Verberg MFG, van der Veen F, Klijn NF, Mercelina PEAM, van Kasteren YM, Nap AW, Brinkhuis EA, Vogel NEA, Mulder RJAB, Gondrie ETCM, de Bruin JP, Sikkema JM, de Greef MHG, ter Bogt NCW, Land JA, Mol BWJ, Hoek A. Randomized trial of a lifestyle program in obese infertile women. N Engl J Med. 2016;374(20): 1942-53. https://doi.org/10.1056/NEJMoa1505297.

42. van Dammen L, Wekker V, van Oers AM, Mutsaerts MAQ, Painter RC, Zwinderman $\mathrm{AH}$, Groen $\mathrm{H}$, van de Beek C, Muller Kobold AC, Kuchenbecker WKH, van Golde R, Oosterhuis GJE, Vogel NEA, Mol BWJ, Roseboom TJ, Hoek A, LIFEstyle study group on behalf of the. Effect of a lifestyle intervention in obese infertile women on cardiometabolic health and quality of life: A randomized controlled trial. PLoS One. 2018;13(1):e0190662. https://doi.org/10.1371/journal.pone.0190662.

43. van de Beek C, Hoek A, Painter RC, Gemke RJBJ, van Poppel MNM, Geelen A, Groen H, Mol BW, Roseboom TJ. Women, their offspring and iMproving lifestyle for better cardiovascular health of both (WOMB project): a protocol of the follow-up of a multicentre randomised controlled trial. BMJ Open. 2018;8(1):e016579.

44. Gray MJ, Litz BT, Hsu JL, Lombardo TW. Psychometric properties of the life events checklist. Assessment. 2004;11(4):330-41. https://doi.org/10.1177/1 073191104269954

45. Buysse DJ, Reynolds CF 3rd, Monk TH, Berman SR, Kupfer DJ. The Pittsburgh sleep quality index: a new instrument for psychiatric practice and research. Psychiatry Res. 1989;28(2):193-213.

46. van Strien T, Frijters JER, Bergers GPA, Defares PB. The Dutch eating behavior questionnaire (DEBQ) for assessment of restrained, emotional, and external eating behavior. Int J Eat Disord. 1986;5(2):295-315. https://doi. org/10.1002/1098-108X(198602)5:2<295::AID-EAT2260050209>3.0.CO;2-T.

47. Bjelland I, Dahl AA, Haug T, Neckelmann D. The validity of the hospital anxiety and depression scale. An updated literature review. J Psychosom Res. 2002;52(2):69-77.

48. Zigmond AS, Snaith RP. The hospital anxiety and depression scale. Acta Psychiatr Scand. 1983;67(6):361-70.

49. Prins A, Bovin MJ, Smolenski DJ, Marx BP, Kimerling R, Jenkins-Guarnieri MA, Kaloupek DG, Schnurr PP, Kaiser AP, Leyva YE, Tiet QQ. The primary care PTSD screen for DSM-5 (PC-PTSD-5): development and evaluation within a veteran primary care sample. J Gen Intern Med. 2016;31(10):1206-11. https://doi.org/10.1007/s11606-016-3703-5.

50. Cohen S, Kamarck T, Mermelstein R. A global measure of perceived stress. J Health Soc Behav. 1983;24(4):385-96.

51. Roberti JW, Harrington LN, Storch EA. Further psychometric support for the 10-item version of the perceived stress scale. J Coll Couns. 2006:9(2):135-47.

52. John OP, Donahue EM, Kentle RL. The big five inventory-versions $4 \mathrm{a}$ and 54. Berkeley: University of California, Berkeley, Institute of Personality and Social Research; 1991.

53. Denissen JJA, Geenen R, van Aken MAG, Gosling SD, Potter J. Development and validation of a Dutch translation of the big five inventory (BFI). J Pers Assess. 2008;90(2):152-7. https://doi.org/10.1080/00223890701845229.

54. Denollet J. DS14: standard assessment of negative affectivity, social inhibition, and type D personality. Psychosom Med. 2005;67(1):89-97. https://doi.org/10.1097/01.psy.0000149256.81953.49.

55. Grundy SM, Cleeman JI, Daniels SR, Donato KA, Eckel RH, Franklin BA, Gordon DJ, Krauss RM, Savage PJ, Smith SC, Spertus JA, Costa F. "Diagnosis and Management of the Metabolic Syndrome." An American Heart Association/National Heart, Lung, and Blood Institute Scientific Statement. Circulation. 2005;112(17):2735-52. https://doi.org/10.1161/circulationaha.1 05.169404 .

56. Braet C, Claus L, Goossens L, Moens E, Van Vlierberghe L, Soetens B. Differences in eating style between overweight and normal-weight youngsters. J Health Psychol. 2008;13(6):733-43.
57. Bogg T, Roberts BW. The case for conscientiousness: evidence and implications for a personality trait marker of health and longevity. Ann Behav Med. 2013;45(3):278-88. https://doi.org/10.1007/s12160-012-9454-6.

58. Esther MF, Karas MJ, McDevitt SC, Guenewald Tara L, Seeman TE. Childhood adversities and adult Cardiometabolic health: does the quantity, timing, and type of adversity matter? J Aging Health. 2015;27(8):1311-38. https://doi. org/10.1177/0898264315580122.

59. Colman I, Kingsbury M, Garad Y, Zeng Y, Naicker K, Patten S, Jones PB, Wild $\mathrm{TC}$, Thompson AH. Consistency in adult reporting of adverse childhood experiences. Psychol Med. 2016;46(3):543-9. https://doi.org/10.1017/s00332 91715002032.

60. Crawford SL, Johannes CB. The epidemiology of cardiovascular disease in postmenopausal women. J Clin Endocrinol Metab. 1999:84(6):1803-12. https://doi.org/10.1210/jcem.84.6.5765-4.

61. Yancura LA, Aldwin CM. Stability and change in retrospective reports of childhood experiences over a 5-year period: findings from the Davis longitudinal study. Psychol Aging. 2009;24(3):715-21. https://doi.org/10.103 7/a0016203.

\section{Publisher's Note}

Springer Nature remains neutral with regard to jurisdictional claims in published maps and institutional affiliations.
Ready to submit your research? Choose BMC and benefit from:

- fast, convenient online submission

- thorough peer review by experienced researchers in your field

- rapid publication on acceptance

- support for research data, including large and complex data types

- gold Open Access which fosters wider collaboration and increased citations

- maximum visibility for your research: over $100 \mathrm{M}$ website views per year

At BMC, research is always in progress.

Learn more biomedcentral.com/submissions 